\title{
A model argument for accurate EF
}

\author{
Geetha Rayarao*, Mark Doyle, Victor Farah, Diane V Thompson, June A Yamrozik, Ronald Williams, Moneal Shah, \\ Robert W Biederman
}

From 19th Annual SCMR Scientific Sessions

Los Angeles, CA, USA. 27-30 January 2016

\section{Background}

CMR still suffers from several sources of inaccuracy in measuring LV volumes and EF. Typical standard deviations (SD) between readers for EF range from 4\% - 7.5\% (Quantification of LV function: Suinesiaputra A, et al. J Cardiovasc Magn Reson. 2015 Jul 28;17(1):63). Further, since the data range of agreement for $95 \%$ of data is 4 SD (i. e. $16 \%-30 \%$ ), it is common practice to adjust EF based on a visual assessment. This presents several major problems in that there is no guarantee that visual EF is a good guide and that adjustments to EDV and ESV will result in the SV being adjusted correctly. Here we present a technique termed 'Removing Endocardial Measured Overage Directionally using External Leverage' (REMODEL) that accomplishes intuitive simultaneous corrections of EF and SV.

\section{Methods}

For a group of patients $(\mathrm{N}=107)$ we applied phase velocity mapping (PVM) to the aorta to calculate SV.

Using previously described aortic coupling conditions, we also calculated EF from the aortic PVM data. These measures were used to estimate EDVest and ESVest using the following simultaneous equations:

\section{$\mathrm{EDVest}=\mathrm{SV} / \mathrm{EF}$}

ESVest $=(\mathrm{SV} / \mathrm{EF})-\mathrm{SV}$

where SV and EF are derived from the aortic PVM data.

These aortic estimates of EDVest and ESVest provide the magnitude and direction of adjustment to apply to the volumetric contours encompassing EDV and ESV (Figure 1). Here, to demonstrate this proof of concept, we manually adjusted the volumetric EF by 1 SD if it was beyond $1 \mathrm{SD}$ of agreement with the aortic calculation.

\section{Results}

The contour-determined EFs ranged from 9\% to 67\%, with corresponding EDV's ranging from $57 \mathrm{ml}$ to

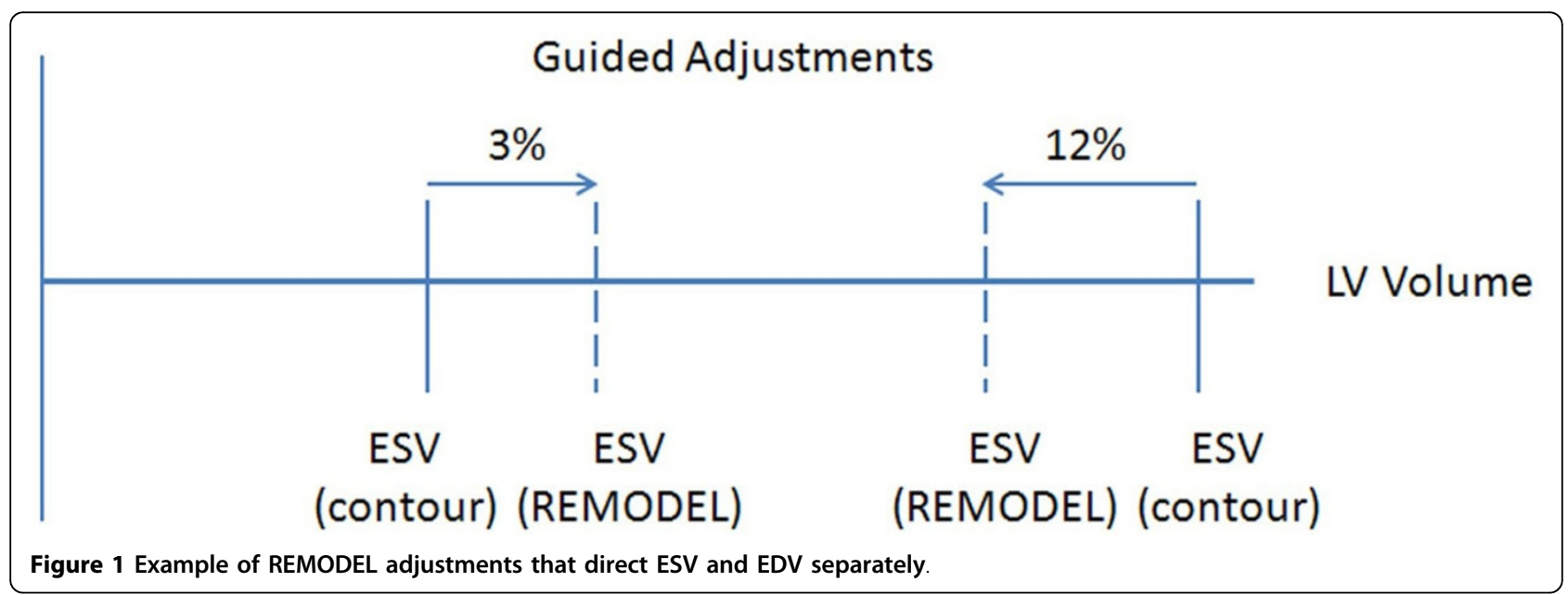

Cardiac MRI, Allegheny General Hospital, Pittsburgh, PA, USA

$525 \mathrm{ml}$ and ESVs ranging from $21 \mathrm{ml}$ to $408 \mathrm{ml}$. The aortic-calculated EF correlated well with the contour- 

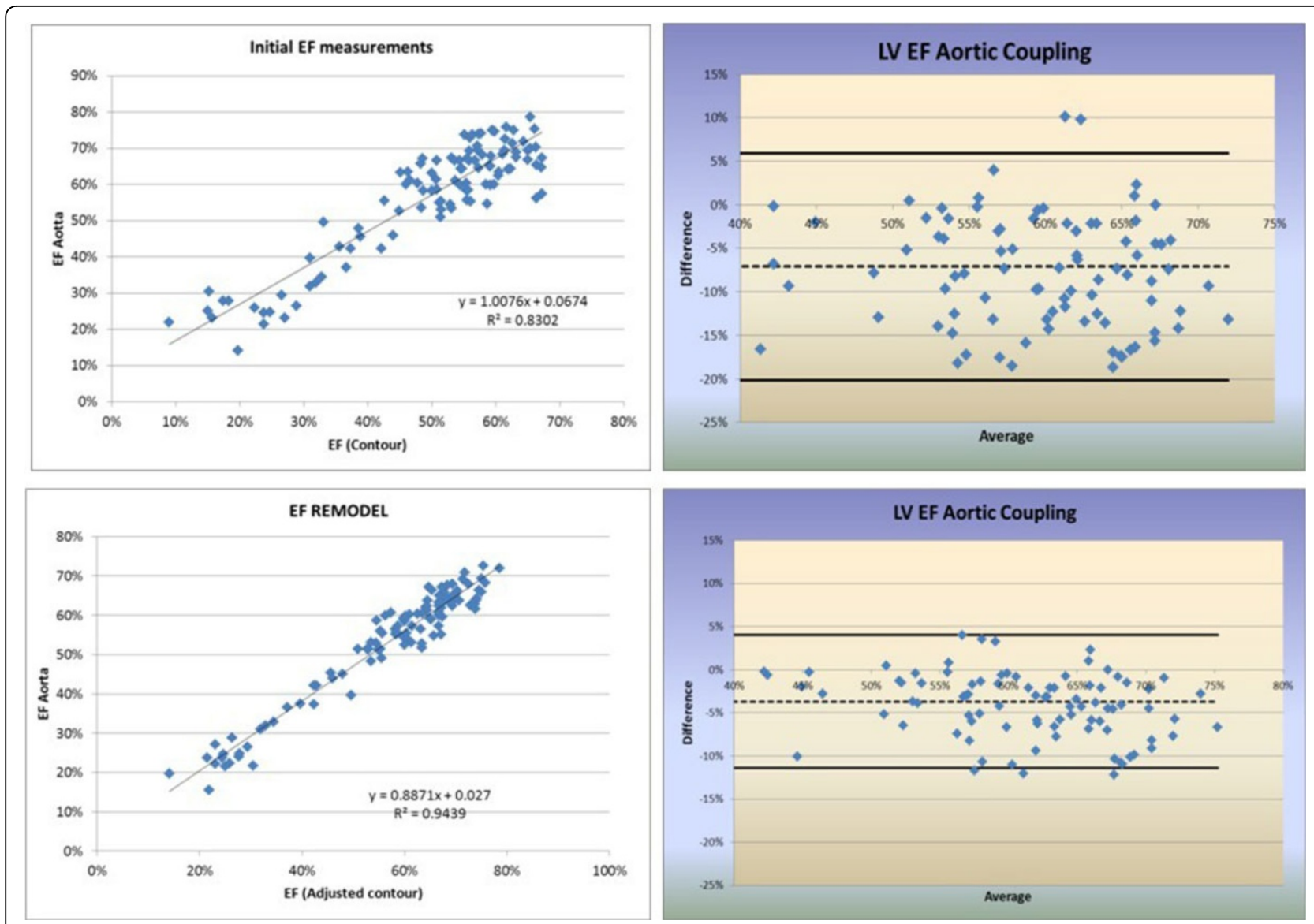

Figure 2 Correlation and Bland-Altman plots for initial and REMODELED data.

measured EF $(\mathrm{r}=0.91)$ with an average difference of $7.1 \%$ and a SD of $6.5 \%$ (Figure 2). Adjusting the contour-measured EF brought it into closer agreement with the aortic-calculated EF $(r=0.96)$ importantly reducing the standard deviation by $42 \%$ to $3.8 \%$. On average, for the cohort, this decreased the LVEF by $3.5 \%(\mathrm{p}<0.001)$.

\section{Conclusions}

By using PVM for aortic calculation of SV and EF, it is possible to re-evaluate EDV and ESV making adjustments to LV contours in a systematic manner that simultaneously brings EF and SV into internal agreement between aortic and LV measures. This approach, which only requires a single additional PVM data set, has immediate clinical implication further improving accuracy and reproducibility of EF.

Published: 27 January 2016

doi:10.1186/1532-429X-18-S1-T12

Cite this article as: Rayarao et al:: A model argument for accurate EF.

Journal of Cardiovascular Magnetic Resonance 2016 18(Suppl 1):T12.
Submit your next manuscript to BioMed Central and take full advantage of:

- Convenient online submission

- Thorough peer review

- No space constraints or color figure charges

- Immediate publication on acceptance

- Inclusion in PubMed, CAS, Scopus and Google Scholar

- Research which is freely available for redistribution 